\title{
Dislocando el mercado sexual: una mirada renovada de la venta y el consumo de sexo en la historia argentina
}

\author{
Displacing the sexual market: a new view of the sale \\ and consumption of sex in the history of Argentina
}

\author{
Ludmila Scheinkman ${ }^{i}$ \\ Doctora en Historia, Instituto de Investigaciones en Estudios de Género/ \\ Universidad de Buenos Aires; Consejo Nacional de Investigaciones Científicas y Técnicas. \\ Buenos Aires - Argentina \\ orcid.org/0000-0002-0897-8914 \\ ludsch@gmail.com
}

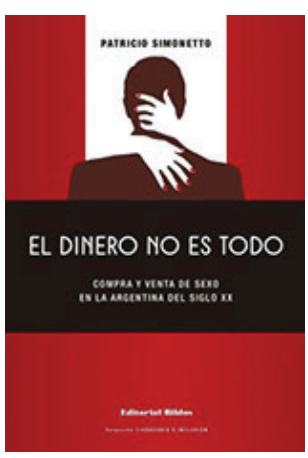

SIMONETTO, Patricio. El dinero no es todo: compra y venta de sexo en la Argentina del siglo $X X$. Ciudad Autónoma de Buenos Aires: Biblos, 2019. 242p.
Los arreglos por los cuales una o varias mujeres accedían a tener sexo con un varón o un grupo de varones a cambio de dinero o bienes variaron en el tiempo y el espacio. Las mujeres, mayormente jóvenes o menores de edad, podían complementar esta actividad, que podía ser ocasional, con otras vías para conseguir ingresos. Podían realizar los actos en sus domicilios, en los de los varones, en bares, sitios laborales o burdeles próximos a destacamentos militares. Con frecuencia hubo intermediación de otros varones maridos, concubinos, rufianes, taxistas -, que se quedaban con parte del dinero, o a veces con todo. Los grados de coacción y violencia implicados en la actividad variaron. Su relación con policías, jueces y el servicio penitenciario parece haber sido frecuente. Catalogadas por los jueces como prostitutas, pocas veces y solo avanzado el siglo se nominaron a sí mismas ante la ley con dicho mote, definiéndose a partir de otras actividades ligadas a lo doméstico.

Como se desprende de este recuento, Patricio Simonetto (2019) ofrece una mirada de la compra y venta de sexo en la Argentina que no se pretende totalizante, exhaustiva ni oclusiva, sino que se presenta ante el lector o lectora como la unión de una serie de historias dispersas y en ocasiones inconexas, que el autor urde en una trama que sin pretensión de completitud, logra dislocar las miradas habituales con las que se ha pensado a dicha actividad y a quienes participaron en ella.

El análisis de la prostitución en Buenos Aires y Argentina no es novedoso, lo cual guarda relación con la gran atención prestada por los propios contemporáneos al fenómeno, que coaguló temores y ansiedades sociales. Trabajos clásicos como el de Donna Guy (1994) inauguraron una mirada crítica en torno a la prostitución legal en Buenos Aires y pusieron foco en el rol del Estado y en las mujeres. Estudios sobre las prácticas médicas 
e higienistas han observado aspectos del periodo de la prostitución patentada, así como de la Ley de Profilaxis que le puso fin, mirando los significados de las enfermedades venéreas y las campañas en su contra (Grammático, 2000; Armus, 2007; Biernat, 2007). Más recientemente, trabajos como los de Cristiana Schettini (2014, abr. 2016) han vuelto sobre el periodo de la prostitución reglamentada para observar la agencia de las mujeres, las reglamentaciones municipales y sus usos por parte de vecinos, funcionarios municipales y policías, las redes transnacionales en las que estaban insertos etc.

Respecto de este corpus temático, que también es recorrido y renovado en sus páginas, El dinero no es todo opera una serie de desplazamientos. En primer lugar, realiza un corrimiento de período, dejando atrás la más explorada prostitución legal, que se desenvolvió entre fines del siglo XIX y la sanción de la ley 12.331 de 1936, la Ley de Profilaxis, para adentrarse en las continuidades y transformaciones en las formas de comprar y vender sexo hasta los años 1980. Para ello, hunde raíces en el periodo reglamentario, observando cómo los lazos allí forjados fueron refuncionalizados cuando la actividad dejó de ser fiscalizada por el Estado. Su trabajo avanza sobre la flexibilización del abolicionismo y el neorreglamentarismo (1937-1955) impulsados por coroneles y militares durante el peronismo para establecer "casas de tolerancia" próximas a los destacamentos militares. Asimismo, ingresa en la consolidación punitiva del abolicionismo (1955-1966), con la sanción de códigos provinciales de faltas y la ampliación del poder policial, que se extendió jurídicamente hasta 1984. Lejos de ceñirse a periodizaciones normativas, muestra cómo quienes participaron de estos mercados dialogaron con las normativas emanadas desde el Estado y los agentes que las pusieron en acto, en una trama de cambios pero también de continuidades en las prácticas y sus sentidos.

En segundo lugar, esta obra produce una dislocación geográfica. Desde las grandes urbes como Buenos Aires o Rosario, que han sido el foco privilegiado de indagación, el trabajo se desplaza en variadas direcciones. Su exploración sobre el proxenetismo conecta grandes ciudades y pueblos del interior de la Argentina, y en particular de la provincia de Buenos Aires, con redes y rutas migratorias que enlazaban Polonia, Río de Janeiro, Montevideo, Francia y otras naciones y ciudades europeas y americanas, así como la atención de la prensa y organismos internacionales como la Sociedad de Las Naciones. Los reclamos militares contra la abolición del sistema reglamentado conectan las profundidades del territorio nacional y los muchas veces aislados destacamentos militares de La Patagonia, San Luis y Corrientes. La pesquisa del autor por los archivos judiciales y penitenciarios permite explorar las experiencias carcelarias y de venta de servicios sexuales de mujeres, así como de compra por parte de trabajadores, en el oeste, centro y sur de la provincia de Buenos Aires, su locus privilegiado. La región más rica y dinámica del país aparece entonces con otro cariz cuando se la mira desde pequeños pueblos rurales o ciudades alejadas del gran centro, mostrando los recorridos laborales masculinos y las experiencias de movilidad geográfica femeninas. Los relatos más conocidos del centro se tensionan así con miradas que desde los márgenes matizan cambios y periodizaciones y muestran la pervivencia de prácticas y sentidos que estaban en transformación entre las clases medias urbanas. 
Un siguiente desplazamiento es el referido a los actores explorados en esta historia. Mientras que la mayoría de las narrativas han privilegiado a agentes estatales - jueces, legisladores, funcionarios, policías - y galenos, así como la exploración de las propias mujeres, esta investigación, que ahonda también en todos ellos, opera un deslizamiento fundamental de las mujeres a los varones implicados en el mercado del sexo. Además de los policías, médicos o proxenetas - la labilidad de esta categoría y la variabilidad de arreglos entre mujeres y varones es señalada -, encontramos maridos, concubinos, militares y fundamentalmente consumidores. En este punto quiero detenerme. Simonetto pone el ojo en la construcción de las masculinidades de los trabajadores - los únicos llamados a testificar en los procesos judiciales explorados -, en sus formas de ocio, en sus relaciones entre pares - los ritos de acceso a la masculinidad, el "debutar", la práctica de ir en grupo a tener sexo de forma no simultánea y por la cual el estatuto de la masculinidad era reactualizado, entre otras. Muestra que la sexualidad masculina fue concebida como "naturalmente" irrefrenable, y que pese a ser realizado en las sombras de la legalidad, el acceso al sexo mediante dinero fue considerado una prerrogativa masculina. Así, ilumina la construcción de la heterosexualidad, indagando en los discursos sobre los supuestos "riesgos" para los varones de la falta de sexo - abstinencia, onanismo, homosexualidad - y del contagio de enfermedades venéreas (donde las prostitutas, como luego las personas no heterosexuales, fueron concebidas el foco transmisor), y la definición de los límites de la sexualidad "normal", que excluía a pobres urbanos, homosexuales, travestis, prostitutas etc. Aquí se percibe la trayectoria previa del autor, quien ya había indagado sobre sexualidades disidentes (Simonetto, 2017), y con esta obra se coloca como un referente en las investigaciones sobre sexualidades en Argentina.

Por último, otra celebrada dislocación promovida en este libro es la que nos aleja de las posiciones dicotómicas que conciben esta práctica como trabajo sexual autónomo o bien como servidumbre. Estas posturas, que han poblado el debate político y cobrado reciente virulencia en el medio local, han tenido también su traducción historiográfica. Simonetto, con habilidad y un anclaje histórico y situado, presenta un universo mucho más lábil que elude el facilismo de las etiquetas y las oposiciones binarias. Reconstruyendo la compleja trama de violencias, asimetrías y desigualdades - raciales, de edad, género, clase y estatus social - en la que cada unos de estos actores sociales estuvieron inmersos, logra aproximarnos a las variadas prácticas y los sentidos asignados a ellas por las propias mujeres - y también el variado arco de varones - que participaron del comercio de sexo en Argentina.

\section{REFERENCIAS}

ARMUS, Diego. La ciudad impura: salud, tuberculosis y cultura en Buenos Aires, 1870-1950. Buenos Aires: Edhasa, 2007.

BIERNAT, Carolina. Médicos, especialistas, políticos y funcionarios en la organización centralizada de la profilaxis de las enfermedades venéreas en la Argentina (1930-1954). Anuario de estudios americanos, v.64, n.1, p.257-288, 2007.
GRAMMÁTICO, Karin. Obreras, prostitutas y mal venéreo: un estado en busca de la profilaxis. In: Gil Lozano, Fernanda; Pita, Valeria Silvina; Ini, María Gabriela (dir.). Historia de las mujeres en la Argentina: siglo XX. Buenos Aires: Taurus, 2000. p.117-135.

GUY, Donna J. El sexo peligroso: la prostitución legal en Buenos Aires 1875-1955. Buenos Aires: Sudamericana, 1994. 
SCHETTINI, Cristiana. Ordenanzas municipales, autoridad policial y trabajo femenino: la prostitución clandestina en Buenos Aires, 1870 1880. Revista Historia y Justicia, v.6, p.72-102. abr. 2016.

SCHETTINI, Cristiana. Conexiones transnacionales: agentes encubiertos y tráfico de mujeres en los años 1920. Nuevo Mundo Mundos Nuevos, 2014. Disponible en: https://doi.org/10.4000/nuevomundo.67440. Acceso en: 9 dic. 2020.

SIMONETTO, Patricio. El dinero no es todo: compra y venta de sexo en la Argentina del siglo XX. Ciudad Autónoma de Buenos Aires: Biblos, 2019.

SIMONETTO, Patricio. Entre la injuria y la revolución: el Frente de la Liberación Homosexual, Argentina, 1967-1976. Quilmes: Universidad Nacional de Quilmes, 2017.

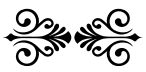

